\title{
Thin Filament
}

National Cancer Institute

\section{Source}

National Cancer Institute. Thin Filament. NCI Thesaurus. Code C33764.

A myofilament composed of actin and tropomyosin. 